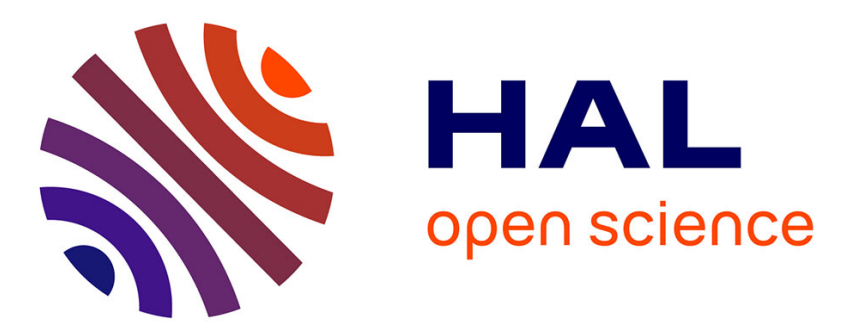

\title{
Morbidity before and after HAART initiation in Sub-Saharan African HIV-infected adults: a recurrent event analysis.
}

Catherine Seyler, Eugène Messou, Delphine Gabillard, André Inwoley, Ahmadou Alioum, Xavier Anglaret

\section{To cite this version:}

Catherine Seyler, Eugène Messou, Delphine Gabillard, André Inwoley, Ahmadou Alioum, et al.. Morbidity before and after HAART initiation in Sub-Saharan African HIV-infected adults: a recurrent event analysis.: HIV morbidity recurrence in Abidjan. AIDS Research and Human Retroviruses, 2007, 23 (11), pp.1338-47. 10.1089/aid.2006.0308 . inserm-00173538

\section{HAL Id: inserm-00173538 https://www.hal.inserm.fr/inserm-00173538}

Submitted on 20 Sep 2007

HAL is a multi-disciplinary open access archive for the deposit and dissemination of scientific research documents, whether they are published or not. The documents may come from teaching and research institutions in France or abroad, or from public or private research centers.
L'archive ouverte pluridisciplinaire HAL, est destinée au dépôt et à la diffusion de documents scientifiques de niveau recherche, publiés ou non, émanant des établissements d'enseignement et de recherche français ou étrangers, des laboratoires publics ou privés. 


\title{
Morbidity before and after HAART initiation in Sub- Saharan African HIV-infected adults: a recurrent event analysis
}

Accepted for publication in AIDS Research and Human Retroviruses

Catherine Seyler ${ }^{1,2}$, MD, PhD, Eugène Messou ${ }^{1,2}$, MD, MPH, Delphine Gabillard ${ }^{2}$, MSc, André Inwoley ${ }^{3}$, PharmD, PhD, Ahmadou Alioum ${ }^{4}$, PhD, Xavier Anglaret ${ }^{1,2}, \mathrm{MD}, \mathrm{PhD}$.

\author{
Author Affiliations : \\ ${ }^{1}$ Programme PAC-CI, Abidjan, Côte d'Ivoire \\ 2 INSERM U593 (epidemiology), Université Victor Segalen Bordeaux 2, Bordeaux, France \\ ${ }^{3}$ Centre de Diagnostic et de Recherches sur le SIDA (CeDReS), Centre Hospitalier \\ Universitaire de Treichville, Abidjan, Côte d'Ivoire \\ ${ }^{4}$ INSERM E0338 (biostatistics), Université Victor Segalen Bordeaux 2, Bordeaux, France
}

\section{Reprints and Correspondence :}

Dr Catherine Seyler

INSERM U593

Université Victor Segalen Bordeaux 2

146 rue Léo Saignat

33076 Bordeaux

France

E-mail : catherine.seyler@club-internet.fr

Running head : HIV morbidity recurrence in Abidjan 
Abstract (250 words)

Background: The incidence and determinants of severe morbidity recurrence in sub-Saharan African HIV-infected adults on antiretroviral therapy (ART) have never been reported.

Methods: Prospective cohort study of HIV-infected adults sin Abidjan. The association of severe morbidity occurrence and recurrence with follow-up CD4 counts and ART on/off status was analyzed by means of multivariate failure analysis for recurrent events (Prentice, Williams and Peterson model).

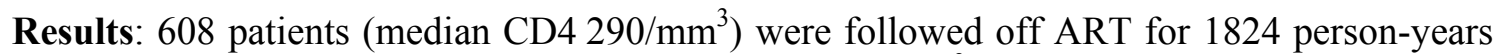
(PY). 187 of them started HAART (median CD4 174/ $\mathrm{mm}^{3}$ ) and were followed for 328 PY. The incidence of first, second and third severe morbidity events was 40.6/100 PY, 68.4/100 PY and 93.9/100 PY during the off-ART period, and 28.4/100, 39.4/100 PY and 37.6/100 during the on-ART period, respectively. The rates of recurrences were higher than the rates of first episodes for almost all diseases, even after stratifying by CD4 count and by ART on/off status. In multivariate analysis, the time-updated CD4 count was independently associated with increasing rates of morbidity first events and recurrences, after adjustment on other covariates $\left(\mathrm{p}<10^{-4}\right)$. By contrast, there was no association between the ART on/off status and the morbidity rates after adjustment on $\mathrm{CD} 4$ count $(\mathrm{p}=0.37)$.

Conclusion: introducing ART led to a clear reduction in morbidity, mainly related to the ART-induced increase in CD4 count. In HIV-infected patients on ART, the incidence of severe morbidity varied with past history of morbidity. Past history of morbidity should be taken into account when comparing HIV-morbidity rates before and after ART initiation.

Key Words: HIV, adults, morbidity, recurrences, sub-Saharan Africa, HAART 


\section{Introduction}

By the end of year 2005 in sub-Saharan Africa, 24.5 million adults were living with HIV/AIDS of whom 810,000 were actually receiving highly active antiretroviral therapy (HAART) (1).

The number of persons receiving HAART in Africa is hopefully likely to rapidly increase. Sub-Saharan African patients who will start HAART within the next few years will be treated in a specific context that differs from the treatment conditions in industrialized countries. These differences relate to the type of health care facilities and access to health care, and to the HIV-morbidity spectrum (2-6). Facilitating access to HAART to millions of persons only makes sense if patients receiving HAART also access prevention and treatment of the most important causes of severe morbidity that occurs on HAART. To better organize the access to global HIV care, it is essential that rates and determinants of morbidity in patients who start HAART should be carefully documented.

This study aimed at estimating the incidences and determinants of severe morbidity, including first episodes and recurrences, in HIV-infected adults before and after HAART initiation in Abidjan, the economic capital city of Côte d'Ivoire.

\section{Methods}

\section{Patients}

The procedures of the Cotrame ANRS 1203 cohort study have been previously described (2, 7). In summary, from 1996 to 2003, HIV-1 or HIV-1+2 infected adults were recruited and followed-up within a therapeutic cohort in Abidjan after written informed consent. Procedures included: monthly visits to the study centre; $\mathrm{CD}^{+}$cell count (CD4 count) every six months; health care free of charge with open access to the study clinic in case of a medical problem; systematic investigation of the vital status of patients lost to follow-up (8); cotrimoxazole prophylaxis (800/160 mg daily) whenever patients reached WHO clinical stage 2 or a CD4 count below 500/ $\mathrm{mm}^{3}$ (9); and, from December 1998, antiretroviral therapy whenever patients reached the criteria for being included in the Côte d'Ivoire/UNAIDS Drug Access Initiative (2). During most of the study period, these criteria were (i) CD4 count $<200 / \mathrm{mm}^{3}$, (ii) WHO clinical stage 4, or (iii) WHO clinical stage 3 and CD4 count at $200-350 / \mathrm{mm}^{3}$. The protocol of the ANRS 1203 study was approved by the ethics committee of the Ivorian National Programme on AIDS, STDs and Tuberculosis and the institutional review board of the French Agency for AIDS research (ANRS, Paris).

In the Cotrame cohort, most patients were prescribed cotrimoxazole either at inclusion or shortly after. For the present study, we considered that cotrimoxazole prophylaxis was now the gold standard for adults at early stages of HIV-infection in sub-Saharan Africa (9). Thus, we chose to exclude the off-cotrimoxazole period from the analyses. Therefore, patients included in the present study were all patients from the Cotrame cohort who started cotrimoxazole, and baseline was the date of cotrimoxazole initiation. The end of the study was October 31, 2003. 


\section{Definitions}

Symptomatic patients were managed at a dedicated outpatients clinic according to standardized algorithms, including laboratory and X-ray investigations, and treatment of the most frequent syndromes. Patients needing a day-time parenteral treatment were managed at the day-care hospital of the study clinic. For life-threatening diseases or for diseases requiring care over night, patients were referred to the Yopougon University Hospital. All clinical events were referred for review to an event documentation committee. An infectious disease was defined as "definitive" when a clinically significant pathogen was isolated, and as "presumptive" when a consistent clinical picture was observed but no pathogen was isolated. The main diagnostic criteria (adapted from CDC and WHO standardized definitions) and laboratory methods used in the Cotrame cohort have been previously described $(2,7,10)$. In this study, we describe "serious morbidity" as all episodes of WHO stage 3 or 4 defining diseases, and any other clinical events leading to at least one day in hospital and/or leading to death (appendix 1).

An episode of a given disease was considered as a new episode if the date of the end of the previous disease episode was separated by more than 30 days from the date of the first symptoms of the new episode. For the following WHO clinical stage 4 defining diseases, recurrences were not defined as new episodes: cryptococcal meningitis, toxoplasmosis, nontuberculous mycobacteriosis, invasive herpes simplex virus or cytomegalovirus diseases, isosporiasis, cryptosporidiosis, lymphoma, Kaposi's sarcoma, chronic or recurrent genital herpes and unexplained weight loss. For tuberculosis, recurrence was considered as a new episode when the previous episode was considered as cured according to international criteria.

\section{Statistical analysis}

For each disease or group of disease, only the three first episodes were considered.

First, second and third episodes were numbered according to their occurrence since the beginning of the entire follow-up period, regardless of the HAART on/off status of the patient at the time the episode occurred; for example, when a first episode of a given disease occurred before HAART was initiated, and a second episode occurred after HAART initiation, the latter is referred to as the "second episode" throughout the manuscript, including when the description focuses on the HAART period.

In the descriptive part of the analysis, we estimated the incidence rate of the first, second, and third episodes of each disease or group of disease overall, during the off-HAART period, and then during the on-HAART period. The incidence rate of a first, second or third episode of a given disease was defined as the number of patients having at least one first, second or third incident episode of this disease per 100 patient-years of "at-risk follow-up". The "at risk period" was defined as follows: (i) For the overall incidence of a given episode of disease during the entire follow-up, the "at risk period" began at baseline for the first episode and at the end of the previous episode for the second and third episodes; the "at risk period" ended at the occurrence of the given episode, or at death, last contact with study team if prior to end of study (October, 31 2003), or end of study for patients who did not have this episode; (ii) For the incidence of a given episode of disease during the off-HAART and on-HAART periods, the same definitions were applied, with two differences: for the on-HAART period, baseline was replaced by the date of HAART initiation, and for the off-HAART period, the end of study was replaced by the date of HAART initiation. 
In the second part of the analysis, we studied the association of mortality and morbidity on the one hand with HAART and current CD4 count on the other hand. A Cox's proportionalhazard regression model was used to study the association of mortality (as the main outcome) with HAART and current CD4 count (as time-dependant covariates), adjusting on baseline characteristics. Due to a significant interaction between HAART and CD4 count in this mortality analysis, we estimated the hazard ratio of death for patients on HAART vs. off HAART, stratified by CD4 count strata. A multivariate failure analysis for recurrent events model (Prentice, Williams and Peterson [PWP] model) (11) was then used to study the association of severe morbidity, including first and recurrent episodes (as the main outcomes) with HAART and current CD4 count (as time-dependant covariates), adjusting on baseline characteristics. In this morbidity analysis, there was no interaction between HAART and CD4 count. In the PWP model, a global p-value covering all episodes of severe morbidity, including the first one and the recurrent ones, was first estimated; then, one hazard ratio (with one p-value) was estimated for each episode (ie: one for the first episode, one for the second episode, and one for the third episode). A PWP model hazard ratio has the same definition as a Cox's model hazard ratio (eg. the hazard ratio of a first episode of morbidity in patients receiving HAART is the risk that a first morbidity event may occur at a given time $t$ for patients who started HAART before the time $t$, relative to the risk at time $t$ for the patient who did not). In this study, we first built a PWP model for the overall severe morbidity. Then, one specific model was built for each specific cause of morbidity. The assumption of proportional hazards was assessed whenever appropriate.

\section{Results}

Of the 723 adults enrolled in the Cotrame ANRS 1203 Cohort from 1996 to 1999, 608 had once started cotrimoxazole prophylaxis and were included in the present study. No patients were excluded from the analyses. Of these 608 patients, 187 started HAART between December 1998 and October 2003. Table 1 shows baseline and follow-up characteristics of the overall patients included in the study and of the group of patients who received HAART. Of the 187 patients who started HAART, 151 (81\%) met the Côte d'Ivoire/UNAIDS Drug Access Initiative criteria for starting treatment, and 36 patients $(19 \%)$ did not meet these criteria. Of the latter, $17(47 \%)$ were at WHO clinical stage 1 or 2 and had a CD4 cell count > $200 / \mathrm{mm}^{3}$, and $19(53 \%)$ were at WHO stage 3 and had a CD4 cell count $>350 / \mathrm{mm}^{3}$ at the time when they initiated HAART.

\section{Morbidity}

During follow-up in the cohort, 1442 severe events were diagnosed in 446 patients, including 272 episodes of severe bacterial diseases (definitive: $n=186$, "presumptive": $n=86$ ), 83 episodes of tuberculosis (definitive: $n=64$, "presumptive": $n=19$ ), 73 episodes of malaria (all definitive), and 30 episodes of non-tuberculous mycobacteriosis (all definitive). The remaining 984 events were: oesophageal candidiasis $(n=114)$, meningeal cryptococcosis $(n=14)$, cerebral toxoplasmosis $(n=5)$, isosporosis $(n=13)$, cryptosporidiosis $(n=9)$, microsporidiosis $(n=6)$, Kaposi's sarcoma $(n=7)$, lymphoma $(n=3)$, chronic Herpes simplex virus (HSV) genital infection $(n=18)$, unexplained weight loss $>10 \%(n=186)$, chronic unexplained diarrhoea $(n=49)$, acute unexplained diarrhoea $(n=147)$, chronic unexplained fever $(n=25)$, acute unexplained fever $(n=177)$, anemia $(n=24)$, non specific meningoencephalitis $(n=27)$, non specific bronchitis $(n=31)$, non specific pneumonia $(n=12)$ and others severe events $(n=166)$. 
Figure 1A shows the overall incidence of first, second and third severe events by HAART on/off status, irrespective of CD4 count. During the off-HAART period, the incidence of first, second and third severe events was 40.6/100 PY, 68.4/100 PY and 93.9/100 PY, respectively; During the on-HAART period, the rate was 28.4/100 PY for the first event, 39.4/100 PY for the second event and 37.6/100 PY for the third event.

Figure 1B shows the incidence of first, second and third severe events by CD4 count, irrespective of the HAART on/off status. In patients with less than $200 \mathrm{CD} 4 / \mathrm{mm}^{3}$, the incidence of first, second and third severe events was 73.3/100 PY, 99.3/100 PY and $110.1 / 100 \mathrm{PY}$, respectively; in patients with more than $350 \mathrm{CD} 4 / \mathrm{mm}^{3}$, the incidence of first, second and third severe events was 24.3/100 PY, 31.4/100 PY and 34.7/100 PY, respectively.

Table 2 shows the incidence rate of the first and second episodes of morbidity irrespective of the HAART on/off status, by time-updated CD4 count, by diseases and groups of diseases. The incidence rate of the second episode tended to be higher than the incidence rate of the first episodes for almost all specific diseases, even after stratifying by CD4 count. This remained true when stratifying by HAART on/off status (data not shown).

Table 3 shows the results of the multivariate failure analysis for recurrent events, studying the association between severe morbidity, HAART, and CD4 count. CD4 count was significantly independently associated with an increasing rate of first severe morbidity events and increasing rates of recurrence, after adjustment on treatment, age, clinical stage, hemoglobin and sex. By contrast, there was no independent association between HAART and severe morbidity occurrence and recurrence, after adjustment on CD4 count.

\section{Mortality}

During the off-HAART period, the mortality rate was $31.6 / 100 \mathrm{P}-\mathrm{Y}(95 \%$ confidence interval [95\% CI] 27.2-36.1) and 7.7/100 P-Y (CI 95\% 5.2-10.3) in patients with CD4 count below $200 / \mathrm{mm}^{3}$ and between 201 and $350 \mathrm{CD} 4 / \mathrm{mm}^{3}$, respectively. During the on-HAART period, these rates decreased to $11.9 / 100 \mathrm{P}-\mathrm{Y}$ (95\%CI 6.5-20.1) and 0.9/100 P-Y (95\%CI 0.02-5), respectively. Due to a significant interaction between HAART and CD4 count in mortality analysis, we estimated the hazard ratio of death for patients on HAART vs. off HAART, stratified by CD4 count strata. HAART was significantly associated with a decrease in mortality, and the hazard ratio of death decreased with increasing CD4 count; in patients with CD4 count at 500, 350 and $200 / \mathrm{mm}^{3}$, the adjusted hazard ratio of death in patients on HAART compared to patients off HAART was $0.05(95 \% \mathrm{CI} 0.00-0.60, \mathrm{p}<0.01), 0.12(95 \% \mathrm{CI}$ $0.02-0.61, \mathrm{p}<0.01)$ and $0.30(95 \%$ CI $0.13-0.67, \mathrm{p}=0.01)$, respectively.

\section{Virological and immunological evolution after HAART initiation}

At six months after HAART initiation, $62 \%$ of patients who started HAART had a plasma HIV-RNA below 200 copies/ml. Figure 2 shows the mean decrease and increase in CD4 count preceding and following HAART initiation in the 187 patients who received HAART. In these patients, the mean increase in CD4 count between HAART and six months initiation was statistically significant $(\mathrm{p}<0.0001)$. 


\section{Discussion}

We followed 608 HIV-infected adults during a median of 40 months in Abidjan, within the framework of a therapeutic cohort study. This cohort was designed to document morbidity, first in patients receiving cotrimoxazole prophylaxis before the HAART national program was launched in Côte d'Ivoire, and then in patients receiving HAART together with cotrimoxazole prophylaxis. Patients were followed-up free of charge in a study care center, and all episodes of morbidity were exhaustively recorded and documented, with standardized criteria applied by an event documentation committee. Measuring the incidence of each of the severe HIV-related diseases within the same group of patients provides a clear picture of the burden of disease in a given population. Before the HAART era, this had been done in only a few cohort studies in sub-Saharan Africa (12-15). To our knowledge, this is the first time that severe morbidity is exhaustively reported both in the pre-HAART and HAART periods, in the same patients, and through recurrent event analyses.

In this cohort we found that: (i) introducing HAART led to a clear reduction in morbidity and mortality; (ii) the dramatic decrease in severe morbidity appeared to be mainly related to the HAART-induced increase in CD4 count $(13,16-18)$; (iii) for a given CD4 count stratum, the short-term spectrum of HIV morbidity appeared to be unchanged before and after HAART was started; (iv) the recurrence rates of all diseases appeared to be higher than the rates of first episodes, even after HAART was started.

Regarding HAART efficacy, a decreasing incidence of tuberculosis has already been reported in South African patients on HAART, compared to the pre-HAART period (19). Our study demonstrates the efficacy of HAART in reducing not only tuberculosis but also the other major causes of HIV morbidity in a sub-Saharan African cohort, as previously shown in industrialized countries $(20,21)$. Our data also demonstrate that a significant rate of severe HIV morbidity persists after HAART initiation, and emphasize the role of the time-updated CD4 count as a key predictor of morbidity occurring under HAART $(22,23)$.

Regarding HIV-morbidity recurrence, recurrence rates of tuberculosis and of pneumococcal invasive diseases have previously been reported to be higher than rates of first episodes in HIV-infected untreated Kenyan adults, $(24,25)$. In our study, we considered up to three episodes of each disease, and we found that the rates of second and third episodes were systematically higher than the rate of first episode for all groups of diseases, even after stratifying by CD4 count and by HAART on/off status. This has three important implications both in terms of patients care and in terms of knowledge on HIV morbidity in Africa. First, for the physicians: when investigating the cause of a given syndrome, physicians should take into account the HAART on/off status, the current CD4 count, but also the past history of morbidity, including the past history of morbidity "off" HAART if the patient is "on" HAART (26-29). Second, for the epidemiologists: in patients on HAART, the first episode of a disease may be the "truly first" episode (no past history of this disease before HAART initiation) or a recurrent episode (this disease already occurred once before HAART initiation). Our findings mean that the incidence of a given disease in a population on HAART may vary depending on the frequency of the past history of this disease in this population. This should be carefully taken into account when comparing rates of morbidity on HAART between different populations and different settings, or within the same population between the pre-HAART and on-HAART periods. Third, for the researchers: the possibility that some patients with past history of a given disease before HAART initiation could benefit 
from a time-limited chemoprophylaxis during the first months on HAART should be explored, as recently suggested for tuberculosis $(30,31)$.

The limits of our data include the following:

First, as our follow-up before HAART initiation was long, a great percentage of patients who started HAART had a first episode of severe morbidity before HAART was initiated. As a consequence, the "at-risk period" for first events on HAART was limited. This may have reduced the statistical power when looking for an association between HAART and morbidity independently from the CD4 count evolution. This could explain why we found that HAART was not independently associated with morbidity while associated with a reduction of mortality independently from immune reconstitution. Another explanation could be the relationship between CD4 count and HAART, as patients with lower CD4 were also more likely to be prescribed HAART. Therefore inclusion of both HAART as a time-dependent coefficient and CD4 count as a time-dependent covariate in the same model may have introduced a bias in the conclusion on the net effect of HAART, even if no statistical interaction was detected between both variables in the morbidity analysis. Further analyses using different statistical methods should explore whether this independent effect of HAART exists in HIV-infected sub-Saharan African adults, as it has been already hypothesized by others $(21,32-34)$.

Second, Hepatitis B virus (HBV) and Hepatitis C virus co-morbidity was not systematically explored. Furthermore, though this was a cohort study with systematic biological and radiological explorations and more available facilities than in most other care centers in Africa, diseases necessitating invasive histological, fibroscopic or radiological explorations remained more difficult to document than more easily accessible infectious diseases. Some specific diseases such as lymphoma or cytomegalovirus invasive infections were thus probably underestimated. In industrialized countries, some rare diseases have been shown to emerge in the medium-term in patients receiving HAART $(21,35)$. Further long-term studies of morbidity in patients on HAART in Côte d'Ivoire should also specifically address HBV comorbidity (36).

Third, the high number of deaths that occurred among patients off HAART may have increased the risk that the rate of serious morbidity occurrence or recurrence in patients on HAART would have been underestimated. This informative censoring may have introduced a bias in the analysis assessing the association between morbidity and HAART

Finally, our cohort procedures included bi-annual CD4 count measurement but no contemporaneous CD4 count and viral load measurement at the onset of clinical episodes. Thus, we were not able to ascertain which percentage of documented diseases could be attributable to the immune reconstitution syndrome, combining atypical clinical presentation with concomitant increasing CD4 count and decreasing plasma HIV-RNA (37-40).

In conclusion, after HAART initiation in this cohort of West African HIV-infected adults, severe morbidity and mortality decreased substantially in relation with immune reconstitution, but significant medium-term rates and recurrence rates of morbidity persisted. The most frequent HIV-related diseases were invasive bacterial diseases and tuberculosis. Our first conclusion is that sub-Saharan African HIV/AIDS care programs should deal with the access to drugs and care against HIV-related diseases as carefully as they do with antiretroviral treatments. 
In HIV-infected patients either "on" HAART or "off" HAART, the incidence of severe morbidity was not only strongly associated with the time-updated CD4 count, but also highly varied with past history of morbidity, including the past history of morbidity "off" HAART if the patient was "on" HAART. Our second conclusion is that, in sub-Saharan Africa, past history of morbidity should be taken into account when comparing overall and specific HIVmorbidity rates between different populations, or when comparing morbidity before and after HAART initiation within the same population. 


\section{Acknowledgements:}

We are indebted to all patients who participated in this study.

We also gratefully acknowledge the valuable contributions of the CeDReS, CEPREF, and INSERM U593 teams: Aka Pierre, Amary Geneviève, Anzian Amani, Bidi Sylvain, Bonard Dominique, Cissé Edwidge, Dakoury-Dogbo Nicole, Diarrassouba Mamadou, Gnokoro JeanCharles, Goli Jeanot, Kassi Marie-Cécile, Konan Lambert, Kouadio Bertin, Kouadio Cheftin, Kouakou Marius, Kouame Agnès, Kosseasse Sidonie, Labibi Georgette, Lehou Jean, Martin Marie-Pierre, Mobio Patrick, N'Chot Célestin, N'Dri-Yoman Thérèse, N'Dri Eric, Nogbout Marie-Pascale, Ouattara Ibrahim, Tchehy Amah-Cécile, Tonwe-Gold Besigin, Toure Siaka, Traore Moussa, Yepié Landry, Yoman Agnès, Zaho Marcel.

This study was supported by the Agence Nationale de Recherches sur le SIDA (ANRS, Paris, France), and the Ivoirian Ministry of Health (Abidjan, Côte d'Ivoire) within the collaborative Programme PAC-CI (grant ANRS 1203).

The sponsor of the study had no role in study design, data collection, data analysis, data interpretation or writing of the report

\section{Contributors:}

C Seyler and X Anglaret sought funding for the study and were responsible for overall study coordination. E Messou, C Seyler and X Anglaret were responsible for patients clinical care in the study centre. A Inwoley led all biological aspects. D Gabillard and A Alioum were the study statisticians. X Anglaret, C Seyler, D Gabillard and A Alioum drafted the manuscript, which all authors subsequently reviewed, edited and approved. 


\section{References}

1. UNAIDS. Report on the global AIDS epidemic. Geneva; 2006. available at: http://www.unaids.org/en/HIV data/2006GlobalReport/default.asp.

2. Seyler C, Anglaret X, Dakoury-Dogbo N, Messou E, Toure S, Danel C, et al. Medium-term survival, morbidity and immunovirological evolution in HIV-infected adults receiving antiretroviral therapy, Abidjan, Cote d'Ivoire. Antivir Ther 2003;8(5):385-93.

3. Kabugo C, Bahendeka S, Mwebaze R, Malamba S, Katuntu D, Downing R, et al. Long-term experience providing antiretroviral drugs in a fee-for-service HIV clinic in Uganda: evidence of extended virologic and CD4+ cell count responses. J Acquir Immune Defic Syndr 2005;38(5):578-83.

4. Coetzee D, Hildebrand K, Boulle A, Maartens G, Louis F, Labatala V, et al. Outcomes after two years of providing antiretroviral treatment in Khayelitsha, South Africa. Aids 2004;18(6):887-95.

5. van Oosterhout JJ, Bodasing N, Kumwenda JJ, Nyirenda C, Mallewa J, Cleary PR, et al. Evaluation of antiretroviral therapy results in a resource-poor setting in Blantyre, Malawi. Trop Med Int Health 2005;10(5):464-70.

6. Bourgeois A, Laurent C, Mougnutou R, Nkoue N, Lactuock B, Ciaffi L, et al. Field assessment of generic antiretroviral drugs: a prospective cohort study in Cameroon. Antivir Ther 2005;10(2):335-41.

7. Anglaret X, Messou E, Ouassa T, Toure S, Dakoury-Dogbo N, Combe P, et al. Pattern of bacterial diseases in a cohort of HIV-1 infected adults receiving cotrimoxazole prophylaxis in Abidjan, Cote d'Ivoire. Aids 2003;17(4):575-84.

8. Anglaret X, Toure S, Gourvellec G, Tchehy A, Zio L, Zaho M, et al. Impact of vital status investigation procedures on estimates of survival in cohorts of HIV-infected patients from Sub-Saharan Africa. J Acquir Immune Defic Syndr 2004;35(3):320-3.

9. WHO. Guidelines on co-trimoxazole prophylaxis for HIV-related infections among children, adolescents and adults in resource-limited settings. Recommendations for a public health approach.

2006; http://www.who.int/hiv/pub/guidelines/ctx/en/index.html.

10. Anglaret X, Dakoury-Dogbo N, Bonard D, Toure S, Combe P, Ouassa T, et al. Causes and empirical treatment of fever in HIV-infected adult outpatients, Abidjan, Cote d'Ivoire. Aids 2002;16(6):909-18.

11. Kelly PJ, Lim LL. Survival analysis for recurrent event data: an application to childhood infectious diseases. Stat Med 2000;19(1):13-33.

12. Mwachari CW, Shepherd BE, Cleopa O, Odhiambo JA, Cohen CR. Mortality and burden of disease in a cohort of HIV-seropositive adults in Nairobi, Kenya. Int J STD AIDS 2004;15(2):120-6.

13. Mermin J, Lule J, Ekwaru JP, Malamba S, Downing R, Ransom R, et al. Effect of cotrimoxazole prophylaxis on morbidity, mortality, CD4-cell count, and viral load in HIV infection in rural Uganda. Lancet 2004;364(9443):1428-34.

14. Corbett EL, Churchyard GJ, Charalambos S, Samb B, Moloi V, Clayton TC, et al. Morbidity and mortality in South African gold miners: impact of untreated disease due to human immunodeficiency virus. Clin Infect Dis 2002;34(9):1251-8.

15. van Oosterhout JJ, Laufer MK, Graham SM, Thumba F, Perez MA, Chimbiya N, et al. A community-based study of the incidence of trimethoprim-sulfamethoxazole- 
preventable infections in Malawian adults living with HIV. J Acquir Immune Defic Syndr 2005;39(5):626-31.

16. Brink AK, Mahe C, Watera C, Lugada E, Gilks C, Whitworth J, et al. Diarrhea, CD4 counts and enteric infections in a community-based cohort of HIV-infected adults in Uganda. J Infect 2002;45(2):99-106.

17. French N, Nakiyingi J, Lugada E, Watera C, Whitworth JA, Gilks CF. Increasing rates of malarial fever with deteriorating immune status in HIV-1-infected Ugandan adults. Aids 2001;15(7):899-906.

18. Whitworth J, Morgan D, Quigley M, Smith A, Mayanja B, Eotu H, et al. Effect of HIV-1 and increasing immunosuppression on malaria parasitaemia and clinical episodes in adults in rural Uganda: a cohort study. Lancet 2000;356(9235):1051-6.

19. Badri M, Wilson D, Wood R. Effect of highly active antiretroviral therapy on incidence of tuberculosis in South Africa: a cohort study. Lancet 2002;359(9323):2059-64.

20. Palella FJ, Jr., Delaney KM, Moorman AC, Loveless MO, Fuhrer J, Satten GA, et al. Declining morbidity and mortality among patients with advanced human immunodeficiency virus infection. HIV Outpatient Study Investigators. N Engl J Med 1998;338(13):853-60.

21. d'Arminio Monforte A, Sabin CA, Phillips A, Sterne J, May M, Justice A, et al. The changing incidence of AIDS events in patients receiving highly active antiretroviral therapy. Arch Intern Med 2005;165(4):416-23.

22. Anastos K, Barron Y, Cohen MH, Greenblatt RM, Minkoff H, Levine A, et al. The prognostic importance of changes in CD4+ cell count and HIV-1 RNA level in women after initiating highly active antiretroviral therapy. Ann Intern Med 2004;140(4):25664.

23. Moh R, Danel C, Sorho S, Sauvageot D, Anzian A, Minga A, et al. Haematological changes in adults receiving a zidovudine-containing HAART regimen in combination with cotrimoxazole in Cote d'Ivoire. Antivir Ther 2005;10(5):615-24.

24. Gilks CF, Godfrey-Faussett P, Batchelor BI, Ojoo JC, Ojoo SJ, Brindle RJ, et al. Recent transmission of tuberculosis in a cohort of HIV-1-infected female sex workers in Nairobi, Kenya. Aids 1997;11(7):911-8.

25. Gilks CF, Ojoo SA, Ojoo JC, Brindle RJ, Paul J, Batchelor BI, et al. Invasive pneumococcal disease in a cohort of predominantly HIV-1 infected female sexworkers in Nairobi, Kenya. Lancet 1996;347(9003):718-23.

26. Gordon MA, Banda HT, Gondwe M, Gordon SB, Boeree MJ, Walsh AL, et al. Nontyphoidal salmonella bacteraemia among HIV-infected Malawian adults: high mortality and frequent recrudescence. Aids 2002;16(12):1633-41.

27. Sonnenberg P, Murray J, Glynn JR, Shearer S, Kambashi B, Godfrey-Faussett P. HIV1 and recurrence, relapse, and reinfection of tuberculosis after cure: a cohort study in South African mineworkers. Lancet 2001;358(9294):1687-93.

28. Grant AD, Charalambous S, Fielding KL, Day JH, Corbett EL, Chaisson RE, et al. Effect of routine isoniazid preventive therapy on tuberculosis incidence among HIVinfected men in South Africa: a novel randomized incremental recruitment study. Jama 2005;293(22):2719-25.

29. Antonucci G, Girardi E, Raviglione MC, Ippolito G. Risk factors for tuberculosis in HIV-infected persons. A prospective cohort study. The Gruppo Italiano di Studio Tubercolosi e AIDS (GISTA). Jama 1995;274(2):143-8. 
30. Seyler C, Toure S, Messou E, Bonard D, Gabillard D, Anglaret X. Risk factors for active tuberculosis after antiretroviral treatment initiation in Abidjan. Am J Respir Crit Care Med 2005;172(1):123-7.

31. Harries AD, Chimzizi RB, Nyirenda TE, van Gorkom J, Salaniponi FM. Preventing recurrent tuberculosis in high HIV-prevalent areas in sub-Saharan Africa: what are the options for tuberculosis control programmes? Int J Tuberc Lung Dis 2003;7(7):61622.

32. Badri M, Bekker LG, Orrell C, Pitt J, Cilliers F, Wood R. Initiating highly active antiretroviral therapy in sub-Saharan Africa: an assessment of the revised World Health Organization scaling-up guidelines. Aids 2004;18(8):1159-68.

33. Cassone A, Tacconelli E, De Bernardis F, Tumbarello M, Torosantucci A, Chiani P, et al. Antiretroviral therapy with protease inhibitors has an early, immune reconstitutionindependent beneficial effect on Candida virulence and oral candidiasis in human immunodeficiency virus-infected subjects. J Infect Dis 2002;185(2):188-95.

34. Skinner-Adams TS, McCarthy JS, Gardiner DL, Hilton PM, Andrews KT. Antiretrovirals as antimalarial agents. J Infect Dis 2004;190(11):1998-2000.

35. Konopnicki D, Mocroft A, de Wit S, Antunes F, Ledergerber B, Katlama C, et al. Hepatitis B and HIV: prevalence, AIDS progression, response to highly active antiretroviral therapy and increased mortality in the EuroSIDA cohort. Aids 2005;19(6):593-601.

36. Rouet F, Chaix ML, Inwoley A, Msellati P, Viho I, Combe P, et al. HBV and HCV prevalence and viraemia in HIV-positive and HIV-negative pregnant women in Abidjan, Cote d'Ivoire: the ANRS 1236 study. J Med Virol 2004;74(1):34-40.

37. French MA, Price P, Stone SF. Immune restoration disease after antiretroviral therapy. Aids 2004;18(12):1615-27.

38. Kumarasamy N, Chaguturu S, Mayer KH, Solomon S, Yepthomi HT, Balakrishnan P, et al. Incidence of Immune Reconstitution Syndrome in HIV/Tuberculosis-Coinfected Patients After Initiation of Generic Antiretroviral Therapy in India. J Acquir Immune Defic Syndr 2004;37(5):1574-1576.

39. Sungkanuparph S, Vibhagool A, Mootsikapun P, Chetchotisakd P, Tansuphaswaswadikul S, Bowonwatanuwong C. Opportunistic infections after the initiation of highly active antiretroviral therapy in advanced AIDS patients in an area with a high prevalence of tuberculosis. Aids 2003;17(14):2129-31.

40. Lawn S, Bekker L, Miller R. Immune reconstitution disease associated with mycobacterial infections in HIV-infected individuals receiving antiretrovirals. Lancet Infect Dis. 2005;5(6):361-73. 


\section{Overall cohort $(n=608)$}

Women, n (\%)

424

(69.7)

Baseline Age (years), median (IQR)

$31 \quad(26-37)$

Baseline WHO clinical stage, n (\%)

26

2

212

3

299

4

71

Baseline CD4 count $\left(/ \mathrm{mm}^{3}\right)^{\dagger}$, median (IQR)

Baseline Hemoglobin (g/L), median (IQR)

Follow-up from baseline to study termination

Cumulative (person-years)

Per patients (months), median (IQR)

40

Status at study termination

Dead, n (\%)

Lost to follow-up*, n (\%)

\section{Patients who started HAART $(\mathrm{n}=187)$}

Women, n (\%)

CD4 count at HAART initiation $\left(/ \mathrm{mm}^{3}\right)^{\dagger}$, median (IQR)

Initial HAART regimen, $\mathrm{n}(\%)$

$$
\begin{array}{ll}
2 \text { NRTIs + 1 PI } & 92 \\
2 \text { NRTIs + 1 NNRTI } & 95
\end{array}
$$

Follow-up from HAART initiation to study termination

Cumulative (person-years)

Per patients (months), median (IQR)

Status at study termination

Dead, n (\%) 


\section{Footnotes for table 1:}

n: number of patients

${ }^{\dagger}$ missing data, $\mathrm{n}=1$

IQR: interquartile range

* Patients lost to follow up tended to be younger $(\mathrm{p}=0.06)$ and at less advanced clinical and immunological stage of disease ( $\mathrm{p}=0.06$ and $\mathrm{p}=0.09$, respectively), though differences between two groups did not reach statistical significance".

NRTIs: nucleosidic reverse transcriptase inhibitors (AZT $+3 \mathrm{TC}, \mathrm{n}=112 ; \mathrm{d} 4 \mathrm{~T}+3 \mathrm{TC}, \mathrm{n}=37$; $\mathrm{d} 4 \mathrm{~T}+\mathrm{ddI}, \mathrm{n}=23$; AZT $+\mathrm{ddI}, \mathrm{n}=15$ )

PI: protease inhibitor (indinavir, $n=49$; nelfinavir, $n=37$; saquinavir, $n=6$ )

NNRTI: non-nucleosidic reverse transcriptase inhibitor (efavirenz, $n=93$ ) 
Table 2: Incidence rate of first and second episodes of diseases irrespective of the HAART on/off status, by time-updated CD4 count

\begin{tabular}{|c|c|c|c|c|c|c|c|c|c|c|c|c|}
\hline \multirow[t]{3}{*}{ Disease } & \multicolumn{6}{|c|}{ First episode } & \multicolumn{6}{|c|}{ Second episode } \\
\hline & \multicolumn{2}{|c|}{$\mathrm{CD} 4>350$} & \multicolumn{2}{|c|}{ CD4 200-350 } & \multicolumn{2}{|c|}{$\mathrm{CD} 4<200$} & \multicolumn{2}{|c|}{$\mathrm{CD} 4>350$} & \multicolumn{2}{|c|}{ CD4 200-350 } & \multicolumn{2}{|c|}{$\mathrm{CD} 4<200$} \\
\hline & IR & $95 \% \mathrm{CI}$ & IR & $95 \% \mathrm{CI}$ & IR & $95 \% \mathrm{CI}$ & IR & $95 \% \mathrm{CI}$ & IR & $95 \% \mathrm{CI}$ & IR & $95 \% \mathrm{CI}$ \\
\hline Bacterial & 5.2 & $(3.5-6.8)$ & 10.5 & $(7.6-13.4)$ & 17.4 & $(14.0-20.9)$ & 7.0 & $(2.6-15.3)$ & 24.9 & $(14.5-39.9)$ & 25.3 & $(16.7-33.9)$ \\
\hline Invasive uro-genital & 1.4 & $(0.7-2.4)$ & 1.6 & $(0.7-3.1)$ & 3.6 & $(2.3-5.3)$ & 3.2 & $(0.1-17.7)$ & 10.7 & $(1.3-38.5)$ & 5.4 & $(0.6-19.5)$ \\
\hline Enteritis & 2.3 & $(1.3-3.6)$ & 2.8 & $(1.5-4.6)$ & 6.1 & $(4.3-8.3)$ & 5.2 & $(0.6-18.9)$ & 3.4 & $(0.1-18.7)$ & 8.4 & $(3.1-18.3)$ \\
\hline Isolated bactaraemia & 1.0 & $(0.4-1.9)$ & 2.2 & $(1.1-3.8)$ & 4.6 & $(3.0-6.2)$ & 0.0 & $(0.0-50.1)$ & 14.7 & $(3.0-42.9)$ & 9.9 & $(2.7-25.4)$ \\
\hline Muco-cutaneous & 0.1 & $(0.0-0.7)$ & 0.5 & $(0.1-1.5)$ & 0.7 & $(0.2-1.6)$ & 0.0 & $(0.0-0.0)$ & 0.0 & $(0.0-0.0)$ & 0.0 & $(0.0-0.0)$ \\
\hline Otitis-Sinusitis & 0.7 & $(0.3-1.6)$ & 2.3 & $(1.2-4.0)$ & 1.8 & $(1.0-3.1)$ & 0.0 & $(0.0-19.3)$ & 5.4 & $(0.1-30.1)$ & 23.9 & $(6.5-61.2)$ \\
\hline Pneumonia & 0.9 & $(0.3-1.8)$ & 3.4 & $(2.1-5.4)$ & 2.5 & $(1.5-4.0)$ & 5.1 & $(0.1-28.4)$ & 7.0 & $-1.0-28.8)$ & 11.7 & $(2.4-34.2)$ \\
\hline Mycobacterial & 1.7 & $(1.0-2.9)$ & 3.7 & (2.3-5.7) & 10.2 & $(7.8-12.7)$ & 0.0 & $(0.0-11.6)$ & 9.1 & $(1.9-26.5)$ & 11.3 & $(4.9-22.3)$ \\
\hline Atypical mycobacteriosis & 0.0 & $(0.0-0.4)$ & 0.9 & $(0.3-2.0)$ & 3.4 & $(2.2-5.1)$ & NA & & NA & & NA & \\
\hline Tuberculosis & 1.7 & $(0.9-2.9)$ & 2.9 & $(1.7-4.8)$ & 6.6 & $(4.6-8.6)$ & 0.0 & $(0.0-12.5)$ & 6.4 & $(0.8-23.0)$ & 9.8 & $(3.6-21.3)$ \\
\hline Constitutional & 14.4 & (11.4-17.4) & 20.1 & $(15.7-24.5)$ & 37.9 & $(32.2-43.6)$ & 10.9 & $(6.7-16.9)$ & 30.4 & $(21.1-42.2)$ & 58.1 & $(46.5-69.8)$ \\
\hline Weight loss $>10 \%$ of UO & 4.3 & $(2.8-5.8)$ & 8.5 & $(6.0-11.1)$ & 18.9 & $(15.4-22.4)$ & NA & - & NA & & NA & \\
\hline Diarrhoea of UO & 2.5 & $(1.5-3.9)$ & 6.5 & $(4.3-8.8)$ & 15.0 & $(11.9-18.1)$ & 1.6 & $(0.0-8.8)$ & 16.2 & $(7.4-30.8)$ & 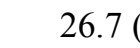 & $(17.6-38.9)$ \\
\hline Fever of UO & 7.0 & $(5.0-8.9)$ & 7.6 & $(5.1-10.0)$ & 11.7 & $(9.0-14.3)$ & 4.5 & $(1.5-10.5)$ & 15.6 & $(7.8-28.0)$ & 22.6 & $(14.0-34.6)$ \\
\hline \multicolumn{13}{|l|}{ Fungal } \\
\hline Stage 4 classifying* & 0.6 & $(0.2-1.4)$ & 1.5 & $(0.6-2.9)$ & 13.2 & $(10.4-16.1)$ & 0.0 & $(0.0-0.0)$ & 8.4 & $(1.7-24.6)$ & 21.6( & $(13.0-33.8)$ \\
\hline Parasitologic & 3.3 & $(2.2-4.9)$ & 2.8 & (1.6-4.6) & 7.5 & (5.4-9.5) & 8.0 & $(2.2-20.5)$ & 16.5 & $(5.4-38.6)$ & 20.2 & $(9.7-37.2)$ \\
\hline Malaria & 2.7 & $(1.6-4.1)$ & 2.2 & $(1.1-3.8)$ & 3.7 & $(2.4-5.5)$ & 7.4 & $(1.5-21.6)$ & 9.3 & $(1.1-33.6)$ & 15.2 & $(4.9-35.4)$ \\
\hline Stage 4 classifying* & 0.2 & $(0.0-0.9)$ & 0.9 & $(0.3-2.1)$ & 2.8 & $(1.7-4.3)$ & 0.0 & $(0.0-60.5)$ & 12.1 & $(0.3-67.7)$ & 24.7 & $(8.0-57.7)$ \\
\hline Other & 0.5 & $(0.1-1.2)$ & 0.2 & $(0.0-1.0)$ & 1.0 & $(0.4-2.0)$ & 0.0 & $(0.0-0.0)$ & 0.0 & $(0.0-0.0)$ & 0.0 & $(0.0-0.0)$ \\
\hline Kaposi's sarcoma & 0.0 & $(0.0-0.4)$ & 0.3 & $(0.0-1.2)$ & 0.7 & $(0.2-1.6)$ & NA & - & NA & - & NA & \\
\hline Viral & 0.1 & $(0.0-0.7)$ & 2.2 & $(1.1-3.8)$ & 2.8 & $(1.7-4.4)$ & 0.0 & $(0.0-46.9)$ & 5.6 & $(0.1-31.4)$ & 17.7 & $(5.7-41.2)$ \\
\hline Genital herpes & 0.1 & $(0.0-0.7)$ & 0.7 & $(0.2-1.8)$ & 1.2 & $(0.6-2.3)$ & NA & - & NA & - & NA & - \\
\hline Herpes zoster & 0.0 & $(0.0-0.4)$ & 1.2 & $(0.5-2.5)$ & 0.7 & $(0.2-1.6)$ & 0.0 & $(0.0-0.0)$ & 0.0 & $(0.0-0.0)$ & 0.0 & $(0.0-0.0)$ \\
\hline Visceral HSV or CMV & 0.0 & $(0.0-0.4)$ & 0.2 & $(0.0-1.0)$ & 0.8 & $(0.3-1.8)$ & NA & - & NA & - & NA & \\
\hline
\end{tabular}




\section{Footnotes for table 2:}

IR: incidence rate, per 100 person-years;

95\% CI: 95\% confidence interval;

NA : non applicable;

UO: unknown origin

HSV: Herpes Simplex Virus

CMV: cytomegalovirus

* See appendix 1 for details on specific diseases included in these group. 
Table 3: Association between severe morbidity first occurrence and recurrences, CD4 count, and HAART on/off status: multivariate analysis

\begin{tabular}{|c|c|c|c|c|c|c|c|c|c|c|c|}
\hline & & \multirow[b]{2}{*}{ Global p } & \multicolumn{3}{|c|}{ First event } & \multicolumn{3}{|c|}{ Second event } & \multicolumn{3}{|c|}{ Third event } \\
\hline & & & $\mathrm{HR}$ & $(95 \% \mathrm{CI})$ & $\mathrm{p}$ & HR & $(95 \% \mathrm{CI})$ & $\mathrm{p}$ & HR & $(95 \% \mathrm{CI})$ & $\mathrm{p}$ \\
\hline \multicolumn{12}{|l|}{$\begin{array}{l}\text { Association with } \\
\text { HAART* }\end{array}$} \\
\hline Overall severe events & $\dagger$ & 0.37 & 1.08 & $(0.62-1.80)$ & 0.78 & 0.76 & $(0.48-1.18)$ & 0.22 & 0.70 & $(0.41-1.21)$ & 0.21 \\
\hline Bacterial & $\dagger$ & 0.01 & 0.89 & $(0.51-1.53)$ & 0.66 & 0.79 & $(0.35-1.81)$ & 0.58 & 0.11 & $(0.02-.43)$ & 0.001 \\
\hline Constitutional & $\dagger$ & 0.81 & 1.05 & $(0.68-1.64)$ & 0.81 & 1.10 & $(0.68-1.77)$ & 0.68 & 0.73 & $(0.33-1.58)$ & 0.42 \\
\hline Mycobacterial & $\circ$ & 0.13 & 0.86 & $(0.43-1.72)$ & 0.68 & 5.67 & $(1.00-32.02)$ & 0.05 & - & - & - \\
\hline Fungal & $\circ$ & - & 0.22 & $(0.05-0.92)$ & 0.04 & - & - & - & & & \\
\hline Parasitic & $\circ$ & 0.72 & 1.24 & $(0.64-2.40)$ & 0.52 & 0.58 & $(0.09-3.55)$ & 0.56 & - & - & - \\
\hline Malignant & $\circ$ & - & 1.29 & $(0.16-10.37)$ & 0.81 & - & - & - & - & - & - \\
\hline Viral & $\dagger$ & 0.48 & 1.49 & $(0.61-3.70)$ & 0.39 & 0.35 & $(0.05-2.66)$ & 0.31 & - & - & - \\
\hline Others & $\dagger$ & 0.48 & 1.25 & $(0.69-2.27)$ & 0.45 & 0.52 & $(0.14-1.92)$ & 0.33 & - & - & - \\
\hline \multicolumn{12}{|l|}{$\begin{array}{l}\text { Association with CD4 } \\
\text { count } * *\end{array}$} \\
\hline Overall severe events & $\dagger$ & $<10^{-4}$ & 0.90 & $(0.88-0.93)$ & $<10^{-4}$ & 0.91 & $(0.87-0.95)$ & $<10^{-4}$ & 0.95 & $(0.90-1.01)$ & 0.08 \\
\hline Bacterial & $\dagger$ & $<10^{-4}$ & 0.90 & $(0.86-0.95)$ & $<10^{-4}$ & 0.94 & $(0.87-1.02)$ & 0.11 & 0.86 & $(0.70-1.06)$ & 0.16 \\
\hline Constitutional & $\dagger$ & $<10^{-4}$ & 0.91 & $(0.88-0.95)$ & $<10^{-4}$ & 0.86 & $(0.81-0.91)$ & $<10^{-4}$ & 0.85 & $(0.77-0.94)$ & 0.002 \\
\hline Mycobacterial & $\circ$ & $<10^{-4}$ & 0.82 & $(0.76-0.89)$ & $<10^{-4}$ & 0.72 & $(0.56-0.93)$ & 0.01 & - & - & - \\
\hline Fungal & $\circ$ & - & 0.59 & $(0.53-0.66)$ & $<10^{-4}$ & - & - & - & - & - & - \\
\hline Parasitic & $\circ$ & $<10^{-4}$ & 0.90 & $(0.85-0.96)$ & $<10^{-4}$ & 0.92 & $(0.76-1.10)$ & 0.34 & - & - & - \\
\hline Malignant & $\circ$ & - & 0.67 & $(0.52-0.86)$ & 0.002 & - & - & - & - & - & - \\
\hline Viral & $\dagger$ & $<10^{-4}$ & 0.83 & $(0.74-0.92)$ & $<10^{-4}$ & 0.73 & $(0.42-1.27)$ & 0.27 & - & - & - \\
\hline Others & $\dagger \dagger$ & 0.29 & 0.96 & $(0.91-1.01)$ & 0.12 & 0.98 & $(0.88-1.08)$ & 0.66 & - & - & - \\
\hline
\end{tabular}




\section{Footnotes for table 3:}

* adjusted on age, sex, baseline haemoglobin, WHO clinical stage, and CD4 count

** for 50 cells $/ \mathrm{mm}^{3}$ higher ; adjusted on age, sex, baseline haemoglobin, WHO clinical stage, and HAART on/off status

Other variables significantly associated with severe morbidity : ${ }^{\dagger}$ WHO clinical stage; ${ }^{\dagger \dagger}$ WHO clinical stage and age; ${ }^{\circ}$ none

HR: Hazard Ratio; 95\% CI: 95\% confidence interval;

p: multivariate failure analysis for recurrent events (Prentice, Williams and Peterson method). A global p-value covering all episodes of severe morbidity, including the first one and the recurrent ones, was first estimated; then, one hazard ratio (with one p-value) was estimated for each episode (ie: one for the first episode, one for the second episode, and one for the third episode). There was one multivariate model of analysis for the overall severe morbidity, and one for each disease (bacterial diseases, tuberculosis and malaria); for each model, we only show here the hazard ratios and p-values for the two main explicative covariates (CD4 count and HAART).

See appendix for details on specific diseases included in each group. 


\section{List of Figures}

Figure 1. Incidence rates of primary and recurrent severe events

Figure 1A. Incidence rates of first, second and third severe events, by HAART on/off status

Figure 1B. Incidence rates of first, second and third severe severe events, by timeupdated CD4 count

Figure 2: CD4 count decrease and increase before and after HAART initiation in patients who started HAART $(\mathrm{n}=187)$

Legend for figure 2:

$0:$ day of HAART initiation

$\triangle \mathrm{CD} 4$ : Mean difference between CD4 count at HAART initiation and CD4 count at a given time before and after HAART initiation 
Figure 1A. Incidence rate of first, second and third severe events, by HAART on/off status

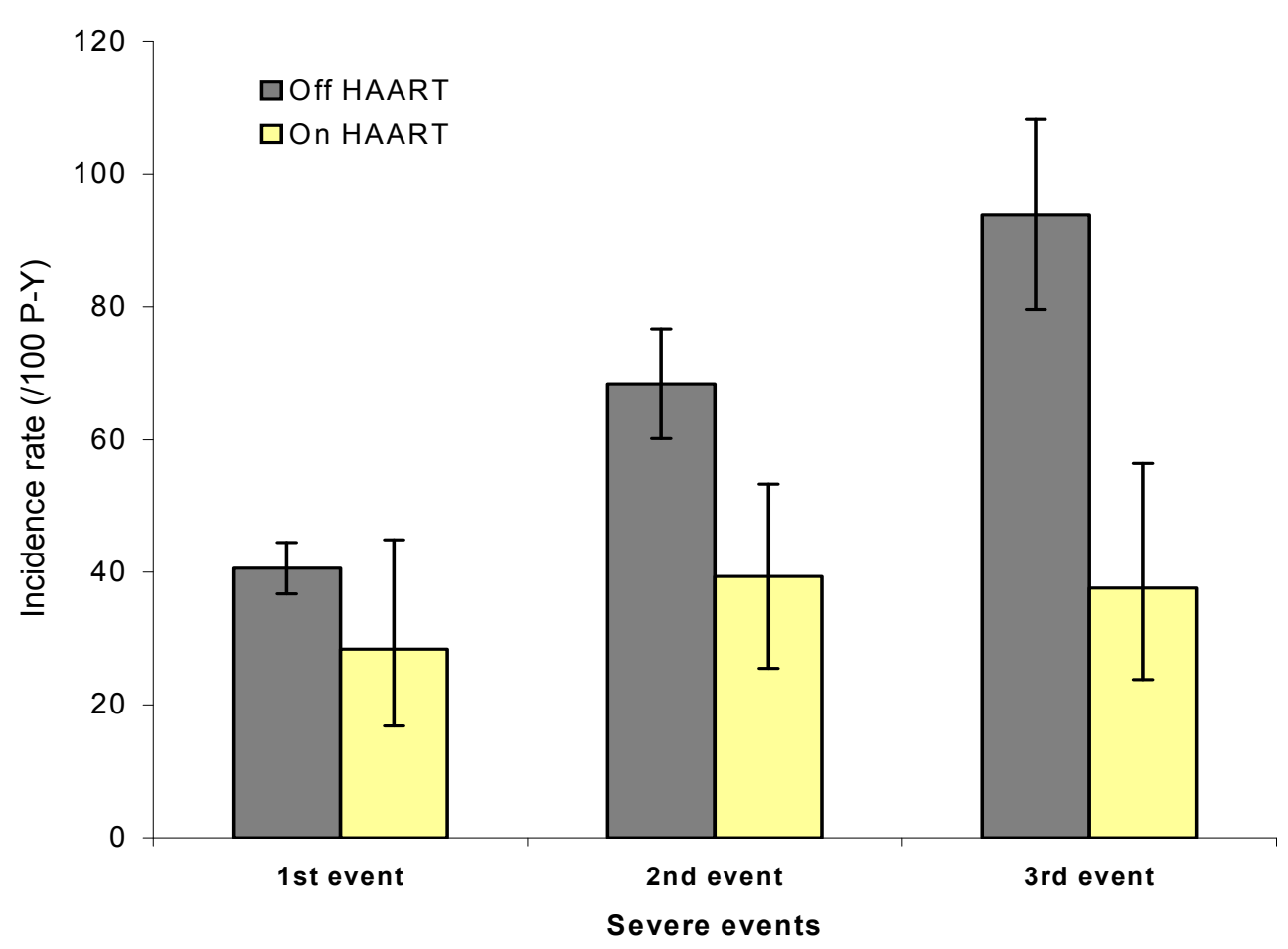


Figure 1B. Incidence rate of first, second and third severe events, by time-updated CD4 count

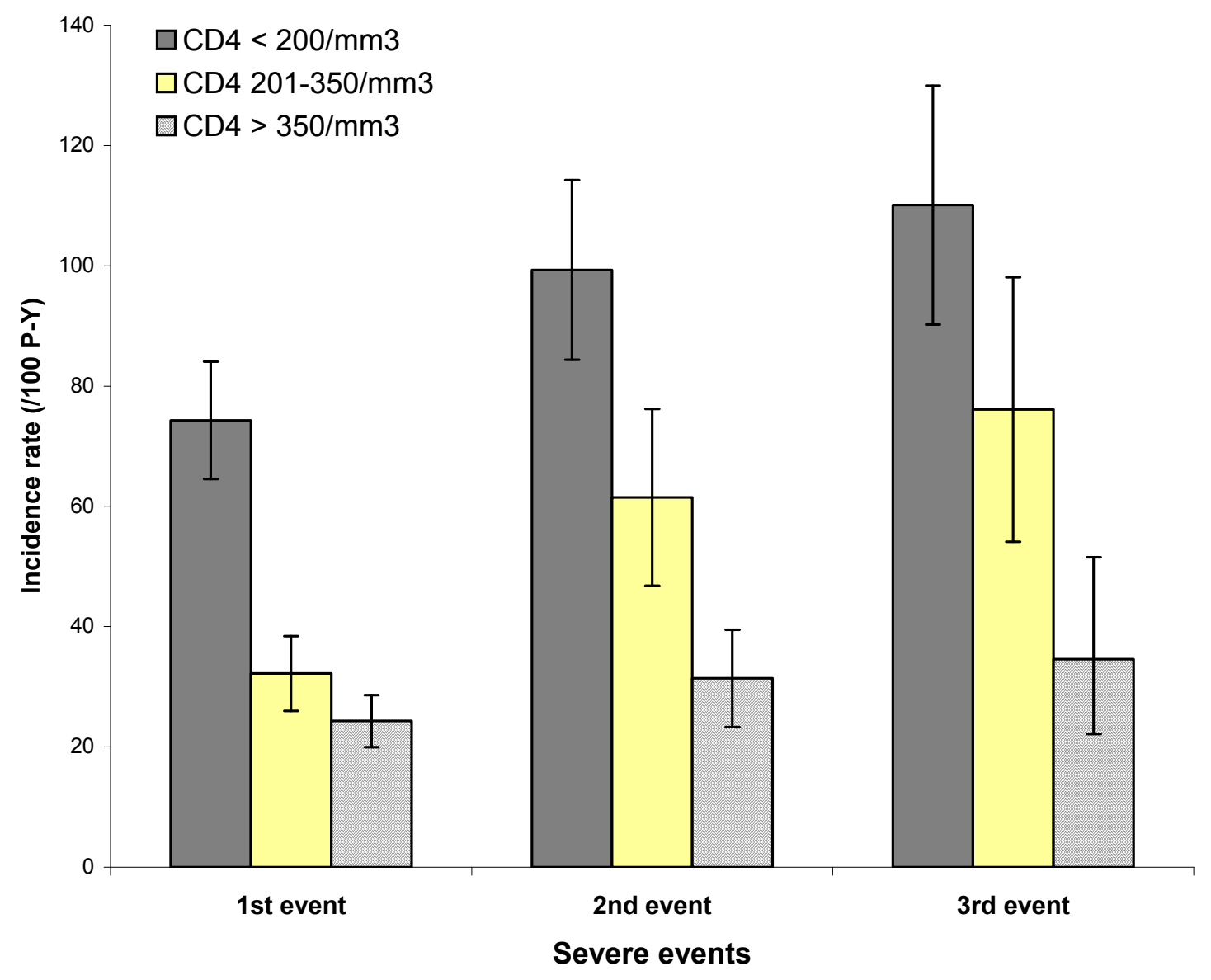


Figure 2. CD4 count decrease and increase before and after HAART initiation in patients who started HAART $(n=187)$

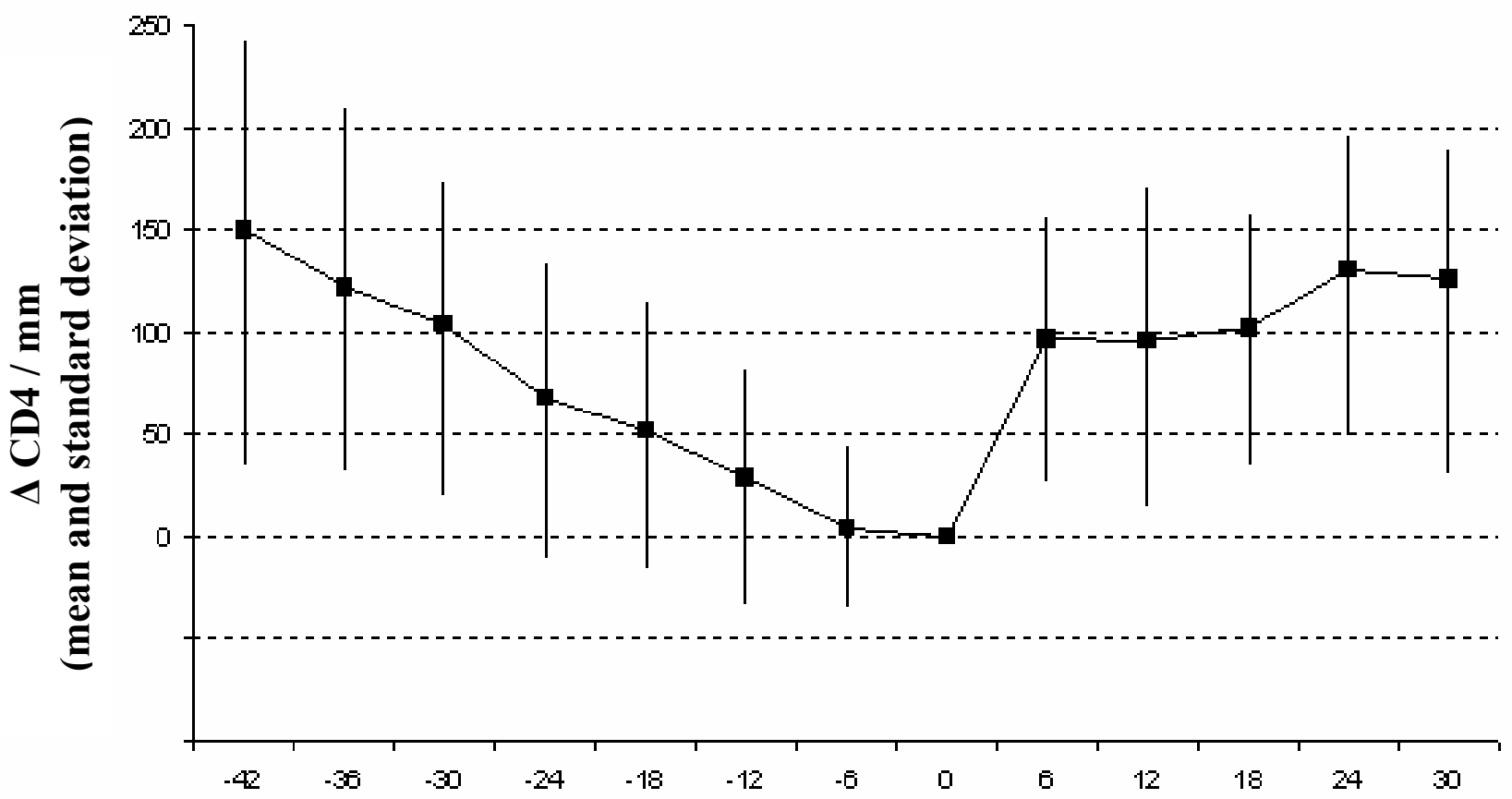

Time (in months) before and after HAART initiation 
Appendix: Severe Diseases classification

\begin{tabular}{|c|c|c|}
\hline Group & Sub-Group & Diseases \\
\hline \multirow[t]{5}{*}{ Bacterial } & Invasive abdomino-uro-genital & $\begin{array}{l}\text { Prostatitis, pyelonephritis, } \\
\text { orchitis/epididymitis, salpyngitis, } \\
\text { enteritis, liver abscess, cholecystitis, } \\
\text { peritonitis }\end{array}$ \\
\hline & \multicolumn{2}{|l|}{ Isolated bacteraemia } \\
\hline & Muco-cutaneous & $\begin{array}{l}\text { Muco-cutaneous abcess with } \\
\text { bacteraemia or with } \mathrm{SC}^{*}\end{array}$ \\
\hline & Otitis-sinusitis & $\begin{array}{l}\text { Otitis or Sinusitis with bacteraemia or } \\
\text { with } \mathrm{SC}^{*}\end{array}$ \\
\hline & Pneumonia & \\
\hline \multirow[t]{3}{*}{ Constitutional } & \multicolumn{2}{|l|}{ Weight loss $>10 \%$ of unknown origin } \\
\hline & Diarrhea of unknown origin & Chronic, or acute with $\mathrm{SC}^{*}$ \\
\hline & Fever of unknown origin & Prolonged, or acute with $\mathrm{SC}^{*}$ \\
\hline \multirow[t]{2}{*}{ Mycobacterial } & Atypical mycobacteriosis & \\
\hline & Tuberculosis & \\
\hline \multirow[t]{3}{*}{ Fungal } & Muco-cutaneous & Oro-pharyngeal candidiasis \\
\hline & & Prolonged vaginal candidiasis \\
\hline & WHO stage 4 classifying & $\begin{array}{l}\text { Oesophageal candidiasis, meningeal } \\
\text { cryptococcosis }\end{array}$ \\
\hline \multirow[t]{3}{*}{ Parasitic } & Malaria & Malaria with SC* \\
\hline & WHO stage 4 classifying & $\begin{array}{l}\text { Cryptosporidiosis, isosporiasis, } \\
\text { pneumocystosis, cerebral toxoplasmosis }\end{array}$ \\
\hline & Others & Any other parasitic disease with $\mathrm{SC}^{*}$ \\
\hline \multirow[t]{5}{*}{ Malignant } & Hepatocarcinoma & \\
\hline & Dysplasia of the uterine cervix & \\
\hline & Carcinoma of the uterine cervix & \\
\hline & Kaposi’s sarcoma & \\
\hline & Lymphoma & \\
\hline \multirow[t]{4}{*}{ Viral } & \multicolumn{2}{|c|}{ Herpes simplex virus (HSV) genital infection } \\
\hline & \multicolumn{2}{|l|}{ Invasive HSV or cytomegalovirus infection } \\
\hline & \multicolumn{2}{|l|}{ Herpes zoster } \\
\hline & Other & Any other viral disease with $\mathrm{SC}^{*}$ \\
\hline
\end{tabular}

* SC: severity criteria: at least one day at hospital, or episode considered as leading to death by the event documentation committee 